\title{
METAMORFOSES DA METRÓPOLE CONTEMPORÂNEA: CONSIDERAÇÕES SOBRE PORTO ALEGRE
}

\author{
Paulo Roberto Rodrigues Soares*
}

\section{RESUMO:}

O artigo discute aspectos da atual reestruturação espacial metropolitana. Nossa intenção é debater algumas tendências das metrópoles contemporâneas levando em consideração as múltiplas faces dos processos genericamente chamados de "reestruturação" espacial. Na atual fase de expansão da economia capitalista globalizada, as metrópoles mundiais reorganizam seus espaços em um contexto de concorrência global por albergar atividades econômicas e serviços avançados. Uma ampla reestruturação periférica e interior das metrópoles é verificada. Nossa intenção é observar com atenção os processos globais para verificar suas conseqüências sociais e seu rebatimento na realidade brasileira. Buscamos, assim, pistas para uma investigação mais aprofundada dos processos de reestruturação nas metrópoles brasileiras. Na parte final do ensaio, apresentamos algumas considerações sobre o caso de Porto Alegre e suas recentes transformações urbanas.

\section{PALAVRAS-CHAVE:}

metropolização, reestruturação espacial, renovação urbana, Porto Alegre (Brasil

\section{ABSTRACT:}

This paper seeks to deal with some faces of the spatial restructuring in the metropolis. We seek to debate some tendencies of the contemporary metropolis taking into account the multiples faces of the process called "spatial restructuring". In the present stage of the expansion of the capitalist globalized economy the world cities improve its spaces in a context of global competition to attract economics activities and advanced services. Both outer and inner city are restructuring. Our purpose is to observe the global processes and their social results as well as its evidences in the Brazilian reality. Thus, we look for evidences to support a research on the processes of restructuring in the Brazilian metropolis. In the final of the paper we present some considerations about the recent urban changes in the city of Porto Alegre.

\section{KEY WORDS:}

metropolization, spatial restructuring, urban renovation, Porto Alegre (Brazil).

Na atual fase de expansão da economia capitalista globalizada, as metrópoles mundiais reorganizam seus espaços em um contexto de concorrência global por albergar atividades econômicas e serviços avançados. Uma ampla reestruturação periférica e interior das metrópoles é verificada, a ponto de diversos autores considerarem que estamos rumando para um novo tipo de forma espacial, a qual estaria superando a tradicional forma das metrópoles estruturadas no período fordista da expansão do capital monopolista. A profusão de neologismos ou o resgate de antigas denominações ("cidade emergente", "cidade dispersa", "cidade difusa", "cidade arquipélago", "pós-metrópole", "pós-suburbia", "exópolis", "metápolis", "cidade-região"), incluem-se entre os esforços teóricos e empíricos de apreensão de uma nova fase da urbanização que se anuncia.

*Doutor em Geografia Humana. Professor do Departamento de Geografia, Instituto de Geociências e do Programa de Pós-graduação em Geografia da Universidade Federal do Rio Grande do Sul (UFRGS). E-mail: paulo.soares@ufrgs.br. 
No presente artigo, tratamos de alguns aspectos da atual reestruturação espacial metropolitana. Nossa intenção é debater algumas tendências das metrópoles contemporâneas levando em consideração as múltiplas faces dos processos genericamente chamados de "reestruturação" espacial. Desde pelo menos dois séculos, as metrópoles conformam os espaços mais complexos da sociedade urbano-industrial. Também constituem-se no lugar das formas mais complexas de sociabilidade. As pautas e processos sociais engendrados nas metrópoles se difundem em escala planetária, especialmente neste atual período de configuração de um "novo tipo de sistema urbano", uma rede urbana mundial de cidades, operando nas escalas global, transnacional e regional (SASSEN, 1994).

Nossa intenção é observar com atenção os processos globais e verificar suas conseqüências sociais e seu rebatimento na realidade local. Buscamos, assim, pistas para uma possível investigação mais aprofundada dos processos de reestruturação nas metrópoles brasileiras. Por esta razão, na parte final do ensaio, apresentamos algumas considerações sobre o caso de Porto Alegre, a "metrópole meridional do Brasil", e suas recentes transformações urbanas.

\section{A morfologia socioespacial das metrópoles}

"...É impossível dizer

em quantas velocidades diferentes

se move uma cidade

a cada instante..."

Sujo)

Ferreira Gullar, "Velocidades" (Poema

Apesar de todo o peso da "metamorfose da morfologia territorial", a "apreensão intuitiva e sentimental" das metrópoles permanece necessária e vigente (JEUDY, 2005:84). Debruçar-se sobre a metrópole é tentar entender e desvendar seus mistérios, seu funcionamento, suas contradições, seus signos, sua linguagem. Mesmo que esta linguagem (ou linguagens) seja um dialeto de códigos diferenciados, inventados e - tal como o enigma da esfinge - quase indecifráveis.

As metrópoles são as formas espaciais/ urbanas mais complexas produzidas pela sociedade capitalista urbano-industrial, pois sua análise "se revela na simultaniedade e multiplicidade de lugares que se justapõem e interpõem, gerando situações de conflito" (CARLOS, 2001:50). As metrópoles são lugares de inovação e experimentação: política, econômica, social, cultural, lingüística, artística, arquitetônica, tecnológica. É na metrópole que a força avassaladora do capital aparece com maior propriedade, justapondo, aniquilando ou subordinando espaços e tempos que não se movimentam no seu ritmo, na sua lógica.

O nascimento da metrópole industrial originou fenômenos sociais até então não experimentados pela humanidade. A enorme concentração de pessoas em um mesmo espaço-tempo, anônimas, trabalhando envolvidas pela grande engrenagem capitalista, exigiu uma nova atitude frente à vida, ao outro, à sociedade e ao mundo. Foi uma racionalização forçada, acompanhada da intensificação da vida nervosa, conforme apontou Georg Simmel em seu ensaio sobre "a metrópole e a vida mental" que em 1903 inaugurou a moderna sociologia/ antropologia urbana.

A metrópole é também o lugar de encontro dos diferentes. É o milieu da mescla e da heterogeneidade social, cultural e étnica, por excelência. $\mathrm{Na}$ passagem do século XIX para o século $X X$, as metrópoles se configuraram como espaços multiculturais e multiétnicos (o melting $p o t)$ através dos movimentos migratórios em escala mundial.

As metrópoles também foram os lugares da luta de classes, dos movimentos operários, de embate das idéias políticas e sociais, de diferentes projetos de sociedade. Foi nas metrópoles que as classes sociais do capitalismo 
industrial mostraram sua força. Se o operariado demonstrava sua capacidade de organização e construção de estratégias políticas de mobilização, a burguesia industrial e financeira também apresentava suas cartas e exercia seu poder na metrópole, especialmente modelando e transformando o espaço conforme seus interesses. Para governar a metrópole, foi necessário que toda sua força econômica e social concentrada se constituísse em um corpo harmônico, racional, ordenado e legível, sendo o controle do espaço a base material deste arranjo (COHEN, 1998:98).

As burguesias e as remanescentes aristocracias estabelecidas na metrópole criaram seus espaços e escreveram no espaço urbano sua epístola de poder, sua ideologia, sua visão de mundo e de sociedade. Nas reformas urbanas de inspiração haussmanniana, as áreas centrais das metrópoles foram moldadas pela burguesia para demarcar o seu poder de classe. Abriram-se avenidas, instalaram-se infra-estruturas, construíram-se edifícios novos que conformaram uma nova paisagem urbana repleta de símbolos de ordem e progresso. No Brasil, exemplos deste processo podem ser observados em espaços como as avenidas Rio Branco (Rio de Janeiro), São João (São Paulo) ou Borges de Medeiros (Porto Alegre), remodeladas nas primeiras décadas do século $X X$.

Foram os burgueses e pequenos burgueses que inauguram a vida pública urbana através da freqüência aos cafés e do footing nos espaços mais privilegiados das metrópoles, que até 1930 coincidiam com as suas áreas centrais. Nos centros das metrópoles, a artéria chic (rua do Ouvidor, no Rio do Janeiro; rua São Bento, em São Paulo ou rua dos Andradas, em Porto Alegre), com seus clubs e caffés, era o lugar de encontro e reunião das elites urbanas. Isto até os pobres, os indesejáveis, as "classes perigosas" também pretenderem exercer seu "direito à cidade", se aproximarem e conquistarem espaços no centro. O que forçou burguesias e aristocratas decadentes a construírem novos centros, novos locais de reunião, distante do contato perigoso, "pecaminoso", com os subalternos e com a escoria da sociedade.

Massimo Cacciari afirmou que a partir de Haussmann a burguesia concebeu a metrópole de forma sectária, como espaço de uma única classe (ela mesma), sob o domínio do capital. A transformação espacial da metrópole, a separação radical dos espaços que a burguesia tentou empreender com as reformas urbanas e com a funcionalização do espaço (bairros aristocratas, bairros burgueses, bairros operários, bairros marginais, zonas comerciais e industriais), representavam a vontade burguesa de instaurar uma nova ordem urbana sob as restritas regras do mercado e do capital, na qual a especulação imobiliária fosse o grande motor do crescimento horizontal e vertical da metrópole (CACCIARI: 1972, 102).

A metrópole é a metra pólis, a "cidade mãe". Ela representa o país, o Estado e a nacionalidade. A imagem da metrópole foi e é utilizada de modo contraditório pelas elites dominantes: em determinados momentos da história, a necessidade de fortalecimento da imagem nacional frente ao exterior faz com que a metrópole (muitas vezes coincidindo com sua condição de cidade-capital) seja alçada e vangloriada pelas elites como símbolo da capacidade empreendedora e construtiva de um povo, de uma nação. Foi assim com a Paris de Napoleão III, com a Berlim prussiana (e, posteriormente, nacional-socialista) e com o Rio de Janeiro, capital federal do Brasil. Entretanto, em outros momentos, de conflitos internos, de acirramento das contradições de classe na escala do Estado-nacional, a metrópole é considerada o lugar dos estrangeiros, dos expatriados e da "miscigenação negativa", contaminadora das qualidades telúricas da nacionalidade, supostamente preservada no interior, na campanha. 


\section{Os caminhos da metropolização brasileira}

As metrópoles brasileiras, inseridas no contexto da modernidade incompleta do capitalismo tardio e inacabado, também passaram (ainda que muitas vezes de forma incipiente ou parcial) por processos semelhantes aos das metrópoles mundiais. Na primeira metade do século $X X$, São Paulo, a metrópole industrial, e Rio de Janeiro, a cidade-capital, estiveram na vanguarda das mudanças sociais (como na semana de arte moderna de 1922), mas também podem ser citadas cidades como Porto Alegre, Recife e Salvador, que tiveram seu desenvolvimento sócio-espacial marcado pela industrialização e pelos fluxos migratórios, tal como foi recorrente em outras realidades urbanas.

As décadas do pós-guerra foram de crescimento populacional acelerado e de concentração de infra-estruturas urbanas e econômicas nas grandes cidades. O crescimento comercial e industrial e o posterior extravasamento da industrialização e dos espaços de assentamento do operariado para os subúrbios foram o embrião da metropolização, mais pronunciada a partir da década de 1960. Este processo de concentração perdurou até meados da década de 1970, quando o fim do milagre econômico e o início da crise que se arrastou por toda a década perdida acenderam "o sinal amarelo" e, com ele, os movimentos sociais e as discussões sobre o caráter desigual e excludente de nossa urbanização e metropolização.

Ao longo da década de 1980, muito se falou da "involução metropolitana", fenômeno que afetava as grandes metrópoles e, especialmente, a metrópole paulista (SANTOS, 1990 e 1991). Tratava-se da queda dos índices de crescimento econômico e populacional das metrópoles, em favor dos demais núcleos urbanos das regiões metropolitanas e das cidades médias. O fenômeno também foi chamado de "reversão da polarização", pois a desconcentração industrial se dava em um movimento centrífugo, ao contrário das tendências centrípetas dominantes entre os anos 1930 e 1970. Também era o período no qual se anunciava a crise da economia industrial fordista, a desindustrialização, e a reestruturação (e em alguns casos o desmonte) da tradicional indústria fordista ( $a$ indústria automobilística como grande ícone), que abandonava suas tradicionais localizações (nos cinturões industriais metropolitanos) em favor de novas localizações, distantes das "deseconomias" da metrópole (força de trabalho organizada, saturação da infraestrutura, custos de localização). Foi a ruptura de um incipiente pacto social que garantia um Estado de bem-estar social mínimo para uma parcela qualificada da força de trabalho urbana. A crise metropolitana se manifestou como crise econômica, ambiental e social, degradando a qualidade de vida e elevando os índices de violência e exclusão nas grandes cidades.

Chegou-se até mesmo a conjeturar sobre o "fim das metrópoles" e o "renascimento" do interior com o deslocamento de uma parte das classes médias para suas principais cidades. Às metrópoles restava a atração que exercia sobre os pobres e populações com baixa qualificação que se inseriam no mercado de trabalho urbano pela informalidade ou pelos serviços malremunerados.

Esta discussão não foi imparcial. Nos primeiros anos da década de 1990 , as políticas neoliberais encontravam maior resistência nas regiões metropolitanas e maior apoio entre os nouveaux riches das cidades médias do interior, especialmente da chamada "região concentrada", o interior paulista e o centro-sul da agricultura capitalista modernizada. Assim, a idéia da reversão da polarização serviu de apoio para uma certa ideologia "anti-urbana" (e "anti-metropolitana") que costuma renascer por parte dos setores conservadores em conjunturas de crise econômica ou política.

Este processo apresentava, também, "evidências espaciais", especialmente na metrópole interior, onde se verificava a acelerada degradação dos centros, ou das áreas centrais tradicionais, e o abandono, por parte 
do capital, das antigas zonas fabris. Estes processos advertiam para um "começo-do-fim" das metrópoles industriais. Uma crise que afetava fortemente a economia política da cidade, levando o operariado fabril a sofrer com fim dos empregos. Também afetou as contas públicas das municipalidades metropolitanas, que submergiram em uma grave crise fiscal. Como resultado do seu poder econômico e das lutas sociais, as metrópoles construíram, no pósguerra, estruturas de bem-estar social bem mais completas que as encontradas em outras cidades. Esta estrutura foi colocada em xeque com o declínio da economia industrial e a conseqüente crise fiscal, combatida com as políticas neoliberais de ajuste e austeridade, afetando a "cidadania metropolitana" das metrópoles fordistas (PERULLI, 1995:24).

\section{Os anos 90 e a mudança de tendências}

De um modo geral, em nível mundial, a década de 1990 marca o "renascimento das metrópoles", pós-crise fiscal e processos de reestruturação econômica. Frente aos impetuosos prognósticos de débâcle e falência geral das grandes cidades apresentados nos anos 80 , podemos afirmar que a metrópole venceu!

A década de 1990 marca a reconcentração econômica nas metrópoles e nas regiões metropolitanas, que, novamente, passam a ser campo de atração de capitais. Porém, como adverte Pierre Veltz (para o caso francês), "a polarização não resulta de uma migração massiva e homogênea de atividades", e sim de processos bastante seletivos, como a implantação de serviços avançados e de funções de gestão (1996:41).

As metrópoles passaram por uma grande reestruturação, processo que não foi unitário ou homogêneo, e no interior do qual, para fins analíticos, seria possível distinguir, pelo menos, duas outras reestruturações: a reestruturação exterior, ou perimetropolitana e a reestruturação interior, ou intrametropolitana.
As reestruturações metropolitanas são produto de outros processos de mudança espacial que ocorreram na economia capitalista no final do século XX. Segundo Neil Brenner (2002), três reestruturações simultâneas afetaram a economia política metropolitana nos Estados Unidos e nos países industriais: a econômica global, a política neoliberal e a da forma urbana.

A "reestruturação econômica global" intensificou os processos de desindustrialização e reindustrialização, bem como os processos de competição e mobilidade do capital nos quais países, regiões e cidades concorrem, globalmente, por investimentos, num já conhecido contexto de "guerra dos lugares". A "reestruturação política neoliberal" produziu o enfraquecimento - quando não o desmonte das políticas estatais de regulação e desenvolvimento, incluindo, aqui, as políticas de desenvolvimento regional e metropolitano, abrindo brecha para que governos locais lato sensu assumissem o papel de coordenação em diversos campos da vida política, econômica e social, tanto com base em um receituário de governance local-global alicerçado no "patriotismo urbano" (conforme apresentado em CASTELLS y BORJA, 1997) como através de políticas públicas, sociais e espaciais "progressistas" e inovadoras.

A "reestruturação espacial da forma urbana" provocou a desconcentração e a reconcentração dos espaços de assentamento e dos complexos de produção, transformando regiões metropolitanas em aglomerações estendidas, multinodais e multicêntricas (BRENNER, 2002).

Esta reestruturação exterior tem sua expressão fenomênica na dispersão e difusão urbanas, com o tecido metropolitano se espalhando sobre o território, elaborando novas formas espaciais no processo de "metropolização do espaço". A escala da região metropolitana se amplia pelas desregulações, pela melhoria dos sistemas de transportes e comunicações, mas, sobretudo, porque se produz um espaço homogêneo, e, 
simultaneamente, fragmentado e hierarquizado, conforme já apontou Henri Lefebvre.

A "nova região metropolitana" manifesta-se sobre o território em diferentes escalas. Na grande escala o território é cada vez mais homogêneo, metropolizado (VELTZ, 1996; LENCIONI, 2004). À pequena escala, verifica-se uma urbanização cada vez mais fragmentada e desigual, na qual os territórios da metrópole estão mais fraturados e incomunicáveis, subvertendo o antigo projeto moderno de urbanismo racional, funcional e unitário. É o colapso da modernização e da idéia de planificação global da cidade substituído pelo urbanismo de projetos, de partes da cidade e pela "gestão" urbana (ARANTES, 2001:121).

No Brasil verificamos a concentração em São Paulo das atividades de gestão e serviços avançados, o domínio paulista na produção científica, acadêmica e cultural, a concentração das atividades e transações comerciais e financeiras. A metrópole de São Paulo se converte indiscutivelmente no ponto de controle do território nacional.

Outras metrópoles nacionais tradicionais (Belo Horizonte, Porto Alegre, Curitiba, Salvador, Fortaleza) verificam um crescimento acima da média dos anos 80 . Estas são acompanhadas pelas novas regiões metropolitanas, pontos de concentração urbana no entorno de capitais e grandes cidades como produto de um processo de difusão da metropolização pelo território. Este processo que é mais intenso no interior paulista com a formação da macro-metrópole (LENCIONI, 2004) ${ }^{1}$.

\section{Reestruturação exterior e as novas figuras da metrópole}

Nas análises sobre a metropolização atual, apresenta-se a tendência global de urbanização dispersa, com a reprodução ad infinitum de assentamentos de baixa densidade, apoiados pelos sistemas de infra-estruturas viárias e de telecomunicações. A cidade como unidade orgânica cinde-se em um centro denso e caótico e uma periferia extensa e homogêna. A "densidade própria da cidade" passa a ser caracterizada pela sua "expansão periférica" (JEUDY, 2005:90). O tecido urbano "invade" antigos territórios rurais suprimindo a dicotomia cidade-campo em uma única lógica territorial.

O fenômeno está associado à submissão do "espaço dos lugares" ao "espaço dos fluxos", à explosão do urbano, assim como à desconcentração e ao caráter extensivo das novas áreas industriais, dos equipamentos coletivos (aeroportos, universidades, centros empresariais, centros comerciais), bem como de externalidades e equipamentos auxiliares aos assentamentos urbanos (aterros sanitários, estações de tratamento de resíduos, represas), entre os quais predominam espaços intersticiais, vazios urbanos, áreas de produção agrícola e de reflorestamento (MONCLÚS, 1998).

O espaço urbano configura-se cada vez mais fragmentado, sem identidade, amorfo, no qual podemos distinguir zonas destinadas a distintos usos e com diferentes conteúdos econômicos e sociais. Conseqüentemente, verifica-se o aumento generalizado da mobilidade e o incremento exponencial da superfície ocupada pelos usos urbanos.

Duas vertentes principais traçam caminhos de interpretação da dispersão urbana: a primeira, vincula a mudança de escala dos fenômenos espaciais, seguindo as sucessivas "ondas" de desconcentração e descentralização verificadas na história da urbanização capitalista; a segunda, relaciona a dispersão urbana com as novas lógicas produtivas (flexibilização, desregulação, desconcentração) e a mudança cultural, na linha proposta por David Harvey (MONCLÚS, 1998).

Aqui cabe a distinção entre urbanização dispersa e desconcentração urbana. O primeiro conceito remete a um processo mais estrito de dispersão do hábitat a partir da implantação de novos assentamentos nos setores periféricos e externos das áreas metropolitanas. O segundo, refere-se a um processo mais amplo 
de desconcentração das atividades econômicas, industriais, comerciais e de serviços, que inaugura uma nova forma de organização territorial, alterando os tradicionais paradigmas de interpretação e intervenção sobre o espaço urbano. Tanto um como outro fomentam uma marcante debilidade dos processos identitários à escala local, bem como severas dificuldades de gestão de um território fragmentado em inúmeras unidades autônomas e nem sempre solidárias, entre as quais, na maioria das vezes, os agentes hegemônicos locais competem entre si pela localização de novas atividades.

A figura da cidade difusa nos remete ao conceito de metápolis, o "novo território urbano", definido por François Ascher como

um conjunto de espaços onde todos ou parte dos habitantes, das atividades econômicas ou dos territórios são integrados ao funcionamento cotidiano (ordinário) de uma metrópole. Uma metápole constitui geralmente, uma 'bacia de empregos', de habitat e de atividades. Os espaços que compõem a metápole são profundamente heterogêneos e não necessariamente contíguos (ASCHER, 1995).

A metápole é resultado de processos de metropolização e de formação de novos territórios urbanos. Apresenta múltiplas formas de crescimento, seja pela extensão ou densificação das periferias, seja pela absorção de núcleos urbanos adjacentes ou distantes das regiões metropolitanas. Caracteriza-se por constituir uma extensa conurbação descontínua, heterogênea e multipolarizada, que induz à homogeneização e à diferenciação: homogeneização porque os mesmos agentes e tipos de agentes econômicos se encontram com as mesmas lógicas em todas as cidades; diferenciação porque nela a competição interurbana é maior, aprofundando as diferenças entre os lugares (ASCHER, 2001:59).

É considerada uma forma espacial que, simultaneamente, sobrepõe e sucede a metrópole fordista. Alguns pesquisadores buscam a gênese desta nova forma espacial em lugares onde, preteritamente, este regime de acumulação sofreu os impactos sócio-espaciais e tecnológicos da reestruturação. Entretanto, as visões de cunho estrutural têm convivido, recentemente, com abordagens que postulam a autonomia da revolução nas tecnologias de com unicação e inform açãó.

Entre as abordagens estruturalistas, as análises mais recentes de Edward Soja sobre o processo de produção socioespacial em Los Angeles serviram para a formulação do conceito de pós-metrópole (SOJA, 2000). O conceito, articula "seis discursos", que remetem a diferentes recortes da realidade metropolitana. Assim, o discurso da exópolis refere-se ao crescimento exterior da metrópole, à produção das cidades de margem e dos exúrbios (assentamentos periféricos aos subúrbios); o conceito de cosmópolis é referente à constituição de uma metrópole interior, socialmente mais complexa e de uma cultura urbana mundial. A flexcity (ou "cidade flexível") refere-se à flexibilização das relações sociais e da gestão do espaço urbano e as metropolaridades são concernentes à ampliação das desigualdades sociais nos espaços urbanos; o arquipélago carcerário alude ao real "cercamento" de amplos setores da metrópole e à construção de "cidades-fortaleza" e a simcity (cidade de simulação) refere-se às paisagens e à vida urbana simulada, cada vez mais realizada em espaços virtuais e de simulação (o ciberespaço, os parques temáticos, os centros comerciais). A pós-metrópole seria a reunião de todos estes discursos em uma mesma entidade territorial ${ }^{3}$.

O modelo das "quatro cidades", proposto por Néstor Garcia Canclini (2000), é outra interessante metáfora da reestruturação metropolitana. Seguindo este modelo, teríamos, sucessivamente, a "cidade histórico-territorial", a "cidade industrial", a "cidade informacional e financeira", as quais não deixam de existir, mas que se justapõem para, como em um palimpsesto, compor a atual metrópole, definida como "a cidade videoclip", onde diferentes realidades, espaços, tempos e culturas 
convivem simultaneamente, formando um quadro socioespacial aparentemente caótico e ilegível (CANCLINI, 2000:88).

\section{urbano metropolitano}

"A metrópole, como um ventre,

espera o desconhecido

e na solidão geométrica

nascem catedrais de ausências"

\section{Ronaldo Cagiano, "Exílios"}

A contemporaneidade das metrópoles está marcada pela "economia simbólica do capitalismo", acompanhada da nova economia dos serviços. A atual fase de investimentos imobiliários nas áreas centrais das metrópoles está relacionada à sua reconstrução, com base em uma nova cultura urbana e metropolitana mundial, a qual também é convertida em atividade econômica. Os processos internos de gentrificação e de recuperação dos centros históricos, também chamados de processos de "revitalização" ou "regeneração" dos centros urbanos, recuperam áreas para o capital imobiliário e trazem de "volta ao centro" atividades econômicas e grupos sociais que haviam se deslocado rumo a outras localizações. A cidade, como forma histórica, e a despeito de suas vicissitudes, se mantem como "objeto de desejo" (AMÉNDOLA, 2000).

Como estratégia de atuação, os capitais financeiros e imobiliários, articulados com os poderes públicos locais, reabilitam antigas construções, as quais fazem parte do patrimônio social construído das cidades histórica e industrial (bairros históricos, prédios públicos, cinemas, agências bancárias, estações ferroviárias, depósitos, fábricas, zonas portuárias), convertendo-as em museus e centros culturais. Busca-se, de todas as maneiras transformar a cidade e o centro em locais de permanente "animação cultural", seja através de projetos que visam o resgate da memória histórica urbana, seja atraindo novos "produtos culturais"4. Estes novos produtos estào, muitas vezes, vinculados à uma produção cultural global, a qual também insere-se em um circuito de "guerra dos lugares" para sua localização em determinadas cidades ${ }^{5}$. Cidades e metrópoles convertem-se em imagens sem passado no espelho da uniformização patrimonial (JEUDY, 2005).

Para Neil Smith, esta "reestruturação da economia espacial-urbana" é produto do desenvolvimento desigual do capitalismo, das mudanças nos estilos de vida e da desvalorização dos investimentos no ambiente construído. Assim, após uma longa fase de maior valorização das localizações externas ao centro, o processo de gentrificação é mais uma expressão do desenvolvimento espacialmente desigual do capitalismo do que, propriamente, um movimento de reversão da tendência à expansão das metrópoles, sendo que, por de trás do processo de gentrificação, se organiza uma estreita coalizão de interesses envolvendo governos, instituições financeiras, incorporadores imobiliários e construtores (SMITH, 1996:263).

Trata-se, em nosso entendimento, de uma forma das "redes de crescimento", alianças estreitamente vinculadas ao processo de reestruturação urbana. O conceito formulado para explicar as coalizões de interesses que atuam nos processos de suburbanização ajusta-se, também, aos investimentos nas áreas centrais. As atividades do setor imobiliário são "produto de uma conjunção complexa de aspectos institucionais do capitalismo e de grupos que se unem para tirar proveito da reestruturação espacial". As "redes de crescimento" constituem uma aliança de interesses políticos e econômicos, públicos e privados, na expansão do ambiente construído, e, na busca de rendas diferenciais urbanas, podem atuar tanto em novas urbanizações como na reutilização do parque imobiliário existente (GOTTDIENER, 1993:220-221). 
Esta nova onda de atração pelo centro responde, também, ao processo de mudança cultural vinculado à emergência da sociedade pós-fordista, o qual afeta a "morfologia social das metrópoles". A diferenciação se amplia e impregna todos os âmbitos da vida social. A divisão social do trabalho se acentua e se expressa tanto em um sem número de especializações profissionais como em um mercado de trabalho global que se vislumbra. Este novo mercado de trabalho é fortemente segmentado. Por um lado, a expansão do setor dos serviços gera um grande número de postos de trabalho com vínculos precários, temporários, pouco especializados e de baixa remuneração ("trabalhos periféricos"), os quais estão de certa forma, atrelados à atividade e ao poder aquisitivo dos profissionais qualificados e especializados das atividades financeiras, de negócios, de gestão e de inovação (os "trabalhos centrais"), vinculadas à economia globalizada (PERULLI, 1995).

Destarte, é possível encontrarmos nas metrópoles diversas "populações urbanas", conforme Martinotti (1994): além dos "habitantes" e dos "pendulares", personagens da metrópole industrial, aparecem, nesta nova fase, os "usuários" e os "homens de negócios" produzidos pela economia financeira globalizada. Estes dois últimos tipos promovem o aumento do número de consumidores da economia de serviços e da economia simbólica da metrópole. Os primeiros como usuários regulares ou esporádicos das funções especializadas que a mesma oferece, desde os serviços de saúde e educacionais até os produtos culturais e de lazer. Os segundos, ao exigirem em seu trânsito pela metrópole, uma ampla reorganização e refuncionalização dos espaços de circulação e de negócios (aeroportos, centros empresariais, hotéis e flats, restaurantes, centros de compras e de lazer), ou seja, a produção de verdadeiros "nãolugares clônicos", presentes em quase todas as metrópoles que exercem funções de nós da rede urbana mundial. São não-lugares produzidos para o uso por indivíduos que atuam com uma racionalidade e uma lógica voltada para o global e que, em seu efêmero contato com os locais desejam se sentir "em casa". Esta produção freqüentemente, está relacionada às mudanças nas áreas centrais e com a produção de novas centralidades.

\section{Algumas considerações sobre a metrópole de Porto Alegre}

Na metrópole de Porto Alegre, capital do estado do Rio Grande do Sul, com mais de 1,5 milhão de habitantes e núcleo de uma região metropolitana de mais de 4 milhões de habitantes, muitas dessas mudanças já podem ser percebidas, acompanhando, em alguns traços, as transformações das economias brasileira e gaúcha, da qual é, indiscutivelmente, o centro de gestão e controle. Entre estas mudanças está uma maior internacionalização da economia e a reestruturação políticoeconômica do aparelho estatal (nas esferas federal e estadual) a partir da adoção do receituário neoliberal. São câmbios que afetam os três sentidos clássioos da cidade: aurbe, a pólis e a civitas.

$\mathrm{Na}$ escala urbano-regional, a desconcentração metropolitana configura-se como realidade, apontando para o processo de formação de uma macro-metrópole ou uma futura "cidade-região" de Porto Alegre. A ocupação industrial segue em marcha rumo aos setores exteriores da Região Metropolitana, especialmente à Caxias do Sul, Santa Cruz do Sul e Lajeado-Estrela, centros urbanos que tendem a formar novas aglomerações urbanas. Também o eixo da BR-290, em direção a Osório (litoral), configura-se como importante área de assentamento industrial, especialmente após a instalação da moderna unidade da General Motors em Gravataí. O mesmo podemos apontar para os novos empreendimentos industriais no Pólo Petroquímico de Triunfo. Estas novas atividades reforçam a gestão no núcleo da metrópole.

$\mathrm{Na}$ escala intra-urbana, no plano da urbe, ao longo da década de 1990 ocorre, em Porto Alegre, um amplo processo de reestruturação 
socioespacial. Contudo, em contraposição às tendências globais, Porto Alegre também destacou-se pela emergência de uma nova correlação de forças no poder local, capitaneado pelo Partido dos Trabalhadores (PT), o qual lançou as bases de um novo modelo de gestão urbana, baseado na democracia direta, tendo como grande "estrela" o "orçamento participativo", pelo qual a cidade foi projetada e reconhecida internacionalmente ${ }^{6 .}$ A tensão entre os dois processos, aparentemente contraditórios, um de tendências globais e outro de emergência de uma nova experiência local, se realizou com avanços, recuos, adaptações e cisões ${ }^{7}$.

A maior internacionalização da economia nacional, processo que afetou fortemente a economia do Rio Grande do Sul nos anos 90, reforçou o papel de Porto Alegre como centro de gestão econômica e territorial. A territorialização de novos grupos empresariais, com escalas globais de atuação, demandou, também, a ampliação ou a instalação de novos serviços para as empresas (agências de propaganda e marketing, escritórios de consultoria), os quais também se desenvolveram no sítio da metrópole.

Surgiram, então, novos setores na metrópole como espaços de gestão: desde centros empresariais, como o edifício Edel Trade Center, até novas centralidades, como a nova sede da Federação das Indústrias do Rio Grande do Sul (FIERGS), localizada no extremo da avenida Assis Brasil, no limite do município e próximo à Free-way (BR-290) e à avenida Carlos Gomes, incluída no arco da "Terceira Perimetral", e um dos eixos preferenciais para a construção de novos conjuntos de escritórios e hotéis de categoria internacional. Com as obras da "Terceira Perimetral", a avenida Carlos Gomes está diretamente conectada com o Aeroporto e a Zona Sul, setor de localização de empreendimentos imobiliários para as classes média e média alta, especialmente condomínios fechados $^{8}$. O próprio Aeroporto Internacional Salgado Filho foi reconstruído, recebendo um novo terminal de passageiros.
Entre as novas centralidades destacase, também, a área do entorno do Shopping Iguatemi, inaugurado em 1984 e que, desde então, atraiu para o seu entorno empreendimentos residenciais de alto padrão. Recentemente, uma grande incorporadora e construtora "ofereceu para a cidade" o Jardim Europa, um novo bairro, planejado e de alto padrão, localizado em uma ampla gleba nas adjacências do shopping e que compreende inúmeros empreendimentos imobiliários no seu interior. Ao longo da década de 1990, com o desenvolvimento imobiliário do eixo da avenida Nilo Peçanha, o entorno do Iguatemi passou a atrair também empreendimentos comerciais, entre os quais destaca-se o Iguatemi Corporate, uma torre de escritórios pós-moderna, considerado o edifício comercial de mais alto padrão na metrópole.

Paradoxalmente, uma parte importante da internacionalização de Porto Alegre pode ser creditada às próprias gestões do Partido dos Trabalhadores na cidade (1989-2004), ou seja, às mudanças na pólis: desde os primeiros movimentos da gestão petista, foram envidados esforços e organizada uma estratégia de inserção da administração local em diversas redes de "cidades mundiais", como Urb-AL e Mercociudades (Mercocidades). Estas redes reúnem governos locais para discussão e solução de problemas comuns, bem como para apresentação de pautas de reivindicação junto a órgãos de fomento internacionais (PNUD e Banco Mundial, por exemplo). Geralmente são apresentadas como entidades que congregam governos locais que se opõem, ao nível da gestão urbana, ao receituário neoliberal, buscando um modelo de governança local participativo e progressista ${ }^{9}$.

Outra estratégia de internacionalização de Porto Alegre foi a organização do Fórum Social Mundial (FSM), reunindo, na cidade, movimentos sociais, organizações nãogovernamentais e partidos políticos internacionais. Boa parte dos participantes das quatro edições do FSM realizadas na cidade (2001, 2002, 2003 e 2005) usufruíram das 
estruturas criadas com a internacionalização da economia (aeroporto, rede de hotéis e restaurantes) e contribuíram para a exportação do "modelo Porto alegre" de gestão urbana especialmente do Orçamento Participativo, vitrine das administrações petistas e premiado mundialmente como "boa prática" de gestão urbana.

A reestruturação espacial intra-urbana da metrópole foi favorecida pela promulgação do novo plano diretor do município (Plano Diretor de Desenvolvimento Urbano e Ambiental PDDUA), em 1996. Com a intenção de instaurar um novo modelo espacial de cidade, densificada, miscigenada e policêntrica, o novo plano diretor inaugurou um novo ciclo da construção civil e da promoção imobiliária na cidade. Destaca-se a divisão da área urbana entre zona norte ("cidade radiocêntrica" e "cidade xadrez") e zona sul ("cidade jardim" e "rururbano"), a qual, para a expansão da construção civil destinada aos setores de maior poder aquisitivo, condicionou os tipos de empreendimentos: ao norte, o desenvolvimento de edifícios de alto padrão, especialmente no bairro Bela Vista, o preferencial de residência dos setores emergentes da cidade; ao sul, a expansão dos empreendimentos do tipo "condomínios fechados"10. A excessiva verticalização de bairros de classe média alta levou à produção de novos movimentos sociais urbanos, os movimentos sociais "dos ricos" visando a preservação do patrimônio construído e da qualidade de vida destes bairros ${ }^{11}$.

Estes processos de especulação imobiliária e de geração de rendas diferenciais urbanas contrastam com a adoção de instrumentos urbanísticos e de gestão urbana (operações urbanas, operações interligadas, regularização fundiária, políticas de habitação popular) que favoreceram os setores de baixa renda da periferia do município, os quais, inegavelmente, obtiveram importantes conquistas em termos de qualidade de vida urbana ao longo dos anos de "administração popular". Todavia, e a despeito destas conquistas, a urbanização desigual e fragmentada seguiu sua marcha, pois as imposições do "modelo global" de gestão se fizeram representar na metrópole.

A "gentrificação" se processa através de diversas operações para resgatar o patrimônio construído e "revitalizar" o centro, abandonado pelos setores de maior poder aquisitivo, tanto para moradia, como para compras e lazer. Assim foi restaurado e recuperado o Mercado Público e construíram-se novos equipamentos culturais, tanto através do poder público estadual e municipal (Memorial do RS), como pela iniciativa privada (destacando-se o Centro Cultural Santander). Pretendeu-se assim, atrair para o centro uma população afastada do mesmo há algumas décadas. Outro projeto importante é o de reconversão da orla portuária em pólo turístico e comercial ${ }^{12}$.

As iniciativas de "renovação" urbana incluem, também, a operação do Shopping Total, no antigo prédio da Cervejaria Continental, além do projeto de construção de novos equipamentos culturais, como o Multipalco do Theatro São Pedro e o novo teatro da Orquestra Sinfônica. Em uma área distante do centro histórico, mas igualmente privilegiada em termos de amenidades (na orla do lago Guaíba, na zona sul), está em andamento a construção da Fundação Iberê Camargo, misto de centro cultural e museu, que reunirá a obra do pintor gaúcho em edifício projetado pelo arquiteto português Álvaro Siza, uma "estrela" da arquitetura mundial.

Ainda na orla do Guaíba e na zona sul, foi anunciado, recentemente, um "mega-projeto" imobiliário, Pontal do Estaleiro, o qual prevê, em um terreno de mais de seis hectares, a construção de cinco edifícios residenciais de 12 andares, três torres comerciais, hotel de categoria internacional, estacionamento com 1.400 vagas e uma área de lazer com marina e restaurantes. O projeto já acende controvérsias e polêmicas urbanísticas e ambientais ${ }^{13}$.

Estes projetos apresentam uma enorme capacidade de reunir interesses comerciais, turísticos e imobiliários, além de envolverem 
parcerias públicas e privadas, legitimando um urbanismo fragmentado em projetos e localizado em pedaços da cidade, em detrimento do planejamento da cidade como totalidade.

No plano do vivido, as novas demandas sociais refletem uma sociedade urbana (a civitas) mais fragmentada e multifacetada, uma segmentação social mais diversificada em múltiplas identidades e territorialidades, sendo que é nos espaços públicos onde os conflitos cotidianos têm lugar.

$\mathrm{Na}$ periferia pobre se recriam identidades com a emergência de diversas estratégias de resistência e inserção na "nova ordem urbana global", com a organização da população em redes de cooperação e solidariedade, centros culturais populares, cooperativas habitacionais, bem como em projetos de inserção social de jovens através de expressões artísticas como a música, o grafitti, o teatro e a dança.

$\mathrm{Na}$ área central, os conflitos entre as atividades informais que ocupam os espaços públicos (camelôs, catadores) e o comércio tradicional, que se diz acuado pela informalidade, leva o poder público a formas de intervenção cada vez mais excludentes, recriando, fora do tempo e do lugar, um discurso urbano muito próximo do higienismo do princípio do século $X X$.

Por outro lado, a inserção dos grupos de maior poder aquisitivo nos circuitos globais leva a sua auto-segregação em setores valorizados da metrópole, tanto nas novas periferias, como em bairros tradicionais de localização das elites onde são produzidos não apenas os setores residenciais novos, mas novas atividades comerciais, de serviços e de lazer exclusivas.

Neste sentido, os conflitos "territoriais" ocorridos no bairro Cidade Baixa, centro nervoso da vida noturna de grande parte da juventude portoalegrense, entre grupos de jovens de cultura alternativa dos bairros centrais e "recém-chegados" da periferia, manifestam as dificuldades de negociação entre diferentes pautas culturais e de comportamento e o quanto as propaladas culturas híbridas ainda estão por negociar seus "espaços" no interior da metrópole ${ }^{14}$.

\section{Palavras finais}

Neste ensaio realizamos uma revisão das principais tendências da metropolização em escala mundial, bem como verificar seu rebatimento, ainda que parcial, na realidade brasileira.

As metrópoles mundiais estão passando por um amplo processo de reestruturação espacial, bem como convivendo com uma nova organização social, muito diferente daquela sobre a qual os referenciais da teoria urbana do século $X X$ foram construídos. Neste sentido, entender a metropolização atual significa compreender estas mudanças e construir, com base no marco teórico legado, um novo marco histórico, geográfico e sociológico de referência. Alguns autores estão tentando esta construção, ainda que, em nossa visão, mais preocupados com as formas derivadas do que com a essência dos processos. Consideramos válido este esforço em um momento de crise do pensamento.

Em nosso trabalho tomamos como exemplo de caso algumas importantes mudanças recentes verificadas na metrópole de Porto Alegre, observando a correspondência destas mudanças com os processos em pauta nas principais metrópoles mundiais.

Consideramos que a morfologia de Porto Alegre se internacionaliza, sua imagem adota referências de estilos dominantes na arquitetura e no urbanismo mundiais. A despeito deste processo, a cidade ainda resguarda diversos pontos de resistência do vernacular. Neste sentido, é importante observar a força de imposição dos modelos urbanos, vetores de um "pensamento único sobre a cidade", no qual as alternativas ao receituário globalizante são estreitas, pela releitura que os agentes locais fazem do modelo e pelo dado receio das administrações de ficarem de fora do exclusivo "banquete das cidades mundiais".

Políticas de renovação urbana, 
reconversão de infra-estruturas, novos espaços de assentamento... se estas mudanças na configuração territorial são bastante pronunciadas, apontando para a adoção de um padrão espacial que se reproduz em escala mundial como "cidade genérica", a vida cotidiana também se altera, especialmente nos setores periféricos, onde face às exclusões provocadas pelo modelo sócioeconômico, resta aos seus habitantes a busca de alternativas e a criação de novas formas de solidariedade e sociabilidade.

Assim, ao percorrermos a cidade nos últimos anos, encontramos evidências importantes de que urbe, pólis e civitas se movimentam. São as metamorfoses da metrópole.

\section{Notas}

1 Sobre o caso de São Paulo ver além do trabalho de S. Lencioni, os demais artigos da obra Globalização e Estrutura Urbana (São Paulo: Hucitec/Fapesp, 2004), bem como o recente livro de N. G. Reis, Notas sobre a urbanização dispersa e novas formas de tecido urbano. São Paulo: Via das Artes, 2006.

2 Dois conceitos têm merecido maior destaque entre estas abordagens: o de Edge City ("cidade de margem") e o de E-topia. A idéia da Edge City, formulada por Joel Garreau (1991) refere-se à "nova fronteira da vida urbana e da sociedade" estadunidense. 0 conceito confere ideologicamente às periferias o atributo de espaços de inovação, de empreendedorismo e independência do Estado. Em contraposição, as cidades centrais são descritas como ambientes pouco inovadores e atrelados ao passado. Já o conceito de E-topia foi proposto por William J. Mitchell (2001) para designar, em tom triunfalista, a nova vida urbana e as novas configurações espaciais do mundo "interconectado eletronicamente". Vislumbrado pelo desenvolvimento das novas tecnologias de informação e comunicação, Mitchell propõe a substituição do atual modelo urbano por e-topias, cidades econômicas e ecológicas que funcionam "de modo inteligente, servidas eletronicamente e conectadas globalmente". Nelas, as atividades da vida urbana (trabalho, compras, lazer, encontros) seriam realizadas on line a partir do ambiente doméstico. Ver J. Garreau, Edge City. Life on the new frontier. New York: Anchor Books, 1991 e W. J. Mitchell, E-topía: "Vida urbana, Jim, pero no la que nosotros conocemos". Barcelona: Gustavo Gili, 2001.
3 Uma questão em aberto é se a forma "pósmetropolitana" representa ou se converterá no paradigma de cidade mundial nas próximas décadas. Em uma primeira aproximação, entendemos que os fenômenos assinalados nos "seis discursos" já estão presentes em outras realidades metropolitanas. Entretanto, consideramos o contexto urbano de Los Angeles tão singular que dificilmente sua morfologia será o padrão da evolução metropolitana em outras realidades sócio-econômicas e históricas. Ver a propósito o debate entre os artigos de J. Curry and M. Kenney, "The Paradigmatic City: Postindustrial Illusion and the Los Angeles School" (Antipode, vol. 31, n 1, p. 1-28, jan-1999) e de A. J. Scott, "Los Angeles and the LA School: A Response to Curry and Kenney" (Antipode, vol. 31, n० 1, p. 29-36, jan-1999).

${ }^{4}$ Sobre este tema ver ainda os artigos de N. Smith "A gentrificação generalizada: de uma anomalia global à regeneração urbana como estratégia urbana global" (In Bidou-Zachariasen, C. De volta à cidade: dos processos de gentrificação às políticas de revitalização dos centros urbanos. São Paulo: Annablume, 2006, p. 59-87); de S. Zukin, "Paisagens urbanas pós-modernas: mapeando cultura e poder" (In Arantes, A. A. O Espaço da Diferença. Campinas: Papirus, 2000, p. 80-103) e de D. Harvey, "A arte como renda: a globalização e transformação da cultura em commodities". In A produção capitalista do espaço. São Paulo: Anna-Blume, 2005, p. 219239.

${ }^{5}$ Este é o caso, por exemplo, do Museu Gughemhein, o qual promove uma verdadeira guerra entre governos locais (prefeituras) para obter 
vantagens na sua localização.

${ }^{6}$ Sobre as questões do PArtido dos Trabalhadores (PT) em Porto Alegre, ver M. L. LAHORGUE, Espaço e Políticas urbanas: Porto Alegre governo do PArtido dos Trabalhadpres. Florianóplis: Universdade federal de Santa Catarina, 2004. (Doutorado em Geografia).

7 Algumas das questões aqui tratadas seguem a linha apresentada em P. R. R. SOARES e V. UEDA, "¿Otra metropolización es posible? Porto Alegre, una metrópoli entre lo local y lo global". In El desafío de las áreas metropolitanas en un mundo globalizado. Barcelona: Institut d'Estudis Territorials, 2003.

8 Sobre a Avenida Carlos Gomes ver E. S. CLARINO e V. UEDA, Dinâmica imobiliária no entorno da Terceira Perimetral em Porto Alegre/RS. Relatório de Pesquisa, Porto Alegre: PROBIC/UFRGS, 2005.

${ }^{9}$ A Rede URB-AL é um programa de cooperação sobre políticas urbanas entre entidades locais da América Latina e União Européia. Foi criada em 1995, reúne cerca de 700 coletividades locais e está dividida em 14 redes temáticas. A prefeitura municipal de Porto Alegre coordena a rede "Financiamento e Orçamento Participativo" (informações sobre a rede URB-AL em www2.portoalegre.rs.gov.br/urbal9/). A Rede Mercocidades também foi criada em 1995 e congrega municípios do Mercosul para "desenvolver o intercâmbio e a cooperação horizontal" entre as municipalidades, contando com 138 cidades associadas nos países do bloco (informações acessadas em www.mercociudades.org).

10 Sobre a expansão dos condomínios fechados e os novos empreendimentos imobiliários em Porto Alegre, ver de V. UEDA, "O mercado imobiliário na cidade de Porto Alegre: os novos empreendimentos e suas transformações no espaço urbano". In Dinâmica Imobiliária e Reestruturação Urbana na América Latina. Santa Cruz do Sul: Edunisc, 2006, p. 92-115.

11 Um dos mais expressivos é o movimento "Salvem Moinhos" organizado no bairro Moinhos de Vento.

12 Embora esteja ainda entravado na dificuldade de articulação dos diversos atores políticos e econômicos.

13 Jornal Zero Hora, Porto Alegre, domingo, 16 de julho de 2006, Caderno de Imóveis, página 2.

14 Estes conflitos envolveram, em 2005, usuários habituais e grupos de jovens homossexuais da periferia da Região Metropolitana na ocupação do espaço público do Shopping Nova Olaria (outro espaço produto da "gentrificação"), point da juventude alternativa porto-alegrense, especialmente os de opção sexual diferenciada.

\section{Bibliiografia}

AMENDOLA, G. La ciudad posmoderna. Madrid: Editorial Celeste, 2000.

ARANTES, O. Urbanismo em fim de linha. $2^{a}$ ed. São Paulo. Edusp, 2001.

ASCHER, F. Metápolis, ou L' avenir des villes. Paris: Editions Odile Jacob, 1995.

ASCHER, F. Les nouveaux principies de I' urbanisme. Paris: L' Aube, 2001.

BORJA, J. e CASTELLS, M. Local y Global. La gestión de las ciudades en la era de la globalización. Madrid: Taurus, 1997.

BRENNER, N. "Decoding the newest 'Metropolitan Regionalism' in the USA: a critical overview". Cities, Vol. 19, No. 1, 2002, p. 3-21.
CACCIARI, M. "Metrópolis". In Tafuri, M., Cacciari, M. e Dal Co, F. De la Vanguardia a la Metrópoli. Crítica radical a la arquitectura. Barcelona: Gustavo Gili, 1972, p. 81-103.

CANCLINI, N. G. "Ciudades multiculturales y contradicciones de lamodernidad". In Imaginarios Urbanos. $3^{a}$. Edición. Buenos Aires: Eudeba, 2000, p.67-104.

CARLOS, A. F. A. Espaço-tempo na metrópole: a fragmentação da vida cotidiana. São Paulo: Contexto, 2001.

CASTELLS, M. y BORJA, J. Local y Global: la gestión de las ciudades en la era de la globalización. Madrid: Taurus, 2000. 
COHEN, P. "In Visible Cities. Urban regeneration and the local subject in the era of multicultural capitalism". In Subculture and Homogenization. Barcelona: Fundació Antoni Tàpies, 1998, p. 93123.

GOTTDIENER, M. A produção social do espaço urbano. São Paulo: Edusp, 1993.

JEUDY, H-P. Espelho das cidades. Rio de Janeiro: Casa da Palavra, 2005.

LENCIONI, S. "O processo de metropolização do espaço. Uma nova maneira de falar da realação entre metropolização e regionalização". In Schieffer, S. Globalização e Estrutura Urbana. São Paulo: Hucitec/Fapesp, 2004, p. 153-165.

MARTINOTTI, G. "The new social morphology of cities". Management of Social Transformations - MOST. Unesco. Discussion Paper Series - No. 16, 1994.

MONCLÚS, F. J. (coord.) La ciudad dispersa: suburbanización y nuevas periferias. Barcelona: Centre de Cultura Contemporània, 1998.

PERULLI, P. Atlas metropolitano. El cambio social em las grandes ciudades. Madrid: Alianza Editorial, 1995.

PREFEITURA MUNICIPAL DE PORTO ALEGRE. Plano Diretor de Desenvolvimento Urbano e Ambiental (PDDUA). Porto Alegre: 1996 (disponível em www.portoalegre.rs.gov.br/spm).

SANTOS, M. "A metrópole: modernização, involução e segmentação". In Valladares L. e Preteceille, E. Reestruturação Urbana. Tendências e desafios. São Paulo: Nobel, 1990.

SANTOS, M. "Involução metropolitana e economia segmentada". In Ribeiro, A. C. T. e Pinheiro Machado, D. Metropolização e Rede Urbana. Perspectivas dos anos 90. Rio de Janeiro: IPPUR/UFRJ, 1991, p. 12-45.

SASSEN, S. Cities in a world economy. Thousand Oaks (CA): Pine Forge Press, 1994.

SIMMEL, G. "A metrópole e a vida mental". In Velho, O. G. (org.) O fenômeno urbano. Rio de Janeiro, Jorge Zahar Editor, 1979, p. 11-25.

SMITH, N. "Gentrification, the frontier, and the restructuring of urban space". In Readings in Urban Theory. Oxford: Blackwell Publishers, 1996 , p. 260-277.

SOARES, P. R. R. e UEDA, V. "¿Otra metropolización es posible? Porto Alegre, una metrópoli entre lo local y lo global". In Orellana, A. (org.) El desafío de las áreas metropolitanas en un mundo globalizado. Una mirada a Europa y América Latina. Barcelona: Institut d'Estudis Territorials, 2003, p. 505-525.

SOJA, E. Postmetropolis. Critical studies on cities and regions. Cambridge (Mass.): Blackwell, 2000.

UEDA, V. "O mercado imobiliário na cidade de Porto Alegre: os novos empreendimentos e suas transformações no espaço urbano". In Silveira, R., Pereira, P. C. X. e Ueda, V. (orgs.) Dinâmica Imobiliária e Reestruturação Urbana na América Latina. Santa Cruz do Sul: Edunisc, 2006, p. 92115.

VELTZ, P. Mundialización, ciudades y territorios. La economía de archipiélago. Barcelona: Ariel, 1996.

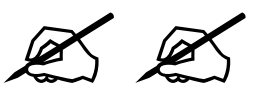

